\title{
Skeletal Actin mRNA Increases in the Human Heart during Ontogenic Development and Is the Major Isoform of Control and Failing Adult Hearts
}

\author{
Kenneth R. Boheler," Lucie Carrier, ${ }^{*}$ Diane de la Bastie," Paul D. Allen," Michel Komajda," \\ Jean-Jacques Mercadier, * and Ketty Schwartz* \\ *Institut National de la Santé et de la Recherche Médicale, U127, Hôpital Lariboisière, 75010 Paris, France; ${ }^{8}$ Service de Cardiologie, \\ Centre Hospitalier Universitaire Pitié-Salpêtrière, 75013 Paris, France; and ${ }^{\ddagger}$ Department of Anesthesiology, \\ Brigham and Women's Hospital, Boston, Massachusetts 02115
}

\begin{abstract}
Expression of the two sarcomeric actins, $\alpha$-skeletal and $\alpha$-cardiac, is regulated in the rodent heart in response to developmental, hormonal, and hemodynamic stimuli. Little is known in man, except that both isogenes were found to be coexpressed in three adult ventricles. In this report, we investigated the isoactin mRNA composition in ventricles from 21 control patients $(4$ fetal, 5 juvenile, 12 adult) and from 15 patients undergoing cardiac transplantation (5 idiopathic dilated cardiomyopathies, 5 ischemic myopathies with myocardial infarcts, 5 diverse etiologies) by two different and complementary techniques: RNA dot blot analysis with specific cDNA probes, and primer extensions with an oligonucleotide common to $\alpha$-cardiac and $\alpha$-skeletal actins. In the case of dot blot analysis, quantification of each isoform was performed by using as standards RNA transcripts obtained from cloned human $\alpha$-actin sequences, and the total amount of sarcomeric actin mRNA was evaluated as a function of total poly $\left(\mathrm{A}^{+}\right) \mathrm{RNA}$. We found that both isogenes are always coexpressed, and that the isoactin pattern changes during development. In utero and in neonatal hearts, $\alpha$-skeletal actin mRNA represents $\leq \mathbf{2 0} \%$ of sarcomeric actins, it increases to $48 \pm 6 \%$ during the first decade after birth and becomes the predominant isoform of adult hearts $(60.4 \pm 8.5 \%)$. The 15 adult failing hearts exhibited the same isoactin pattern as the control ones $(62.84 \pm 11.06 \%)$, and there was no difference in expression between patients with dilated cardiomyopathy or ischemic heart disease. These observations demonstrate that cardiac development in man, in contrast to rodent heart, is characterized by an up-regulation of the skeletal actin gene, the expression of which does not change in hypertrophied and failing hearts, and suggest that the actin and myosin heavy chain families are independently regulated in human heart. (J. Clin. Invest. 1991. 88:323-330.) Key words: skeletal, and cardiac actin mRNAs • primer extension assay • dot blot analysis • fetal, neonatal, adult human hearts • end-stage heart failure
\end{abstract}

A portion of this work was presented in abstract form at the 63rd Scientific Sessions of the American Heart Association, Dallas, TX, 1215 November 1990.

Address reprint requests to Kenneth R. Boheler, INSERM U127, Hôpital Lariboisière, 41 Boulevard de la Chapelle, 75010 Paris, France.

Received for publication 13 September 1990 and in revised form 27 February 1991.

J. Clin. Invest.

(C) The American Society for Clinical Investigation, Inc.

0021-9738/91/07/0323/08 \$2.00

Volume 88, July 1991, 323-330

\section{Introduction}

Sarcomeric actins are major components of the thin filaments of striated muscle, and it is the regulated interactions of actins by tropomyosin and the troponin complex with myosins of the thick filament which are responsible for contraction and the generation of force. Changes in any of these interactions by intracellular events or changes in the expression of the contractile element genes can potentially lead to profound changes in the contractile properties of cardiac muscle. Until now, most attention has been focused on the striking diversity in the pattern of expression for myosin heavy chain isogenes, but the multigene families encoding the other contractile proteins, and more specifically actin, have been studied to a lesser extent (reviews in references 1 and 2).

Two sarcomeric actins, $\alpha$-cardiac and $\alpha$-skeletal, are the preponderant actin isoforms detected in the striated muscle of mammals and birds (review in reference 3). These two isoforms are encoded by different genes, and as expected for any protein with such an important role in the function of striated muscle cells, the nucleic acid sequence is highly conserved. These two isoactins, however, differ markedly in the $5^{\prime}$ and $3^{\prime}$ untranslated regions of the RNA, and by four amino acids at the protein level two of which are located at the amino terminus, the region of the molecule that interacts with myosin during contraction. The amount of the isoforms and the respective mRNAs present varies with species, muscle type, development, and aging. In the rat, $\alpha$-skeletal actin mRNAs account for as much as $50 \%$ of the total at birth that rapidly decreases to levels of $<10 \%$ in the adult (4-7). After the imposition of a chronic hemodynamic overload $(5,8,9)$ or the injection of thyroid hormone $(10)$, $\alpha$-skeletal actin mRNAs rapidly accumulate in rat ventricles and in the case of overload the accumulation is transient $(5,8)$. In cultured neonatal cardiomyocytes, $\alpha$-skeletal actin mRNAs accumulate after the administration of $\alpha 1$-adrenergic agonists (6) or growth factors TGF $\beta 1$ and bFGF (11).

In human hearts, much less is known concerning the amounts of the actin mRNAs present during development, with age, or in disease states. Gunning et al. (12) reported that the amount of $\alpha$-skeletal and $\alpha$-cardiac actin mRNAs were nearly identical in the heart of a patient suffering from hypertrophic obstructive cardiomyopathy, and Bennetts et al. (13) reported that $\alpha$-skeletal actin represented $\sim 20 \%$ of the total $\alpha$-actin RNA in a patient who died from fatal head injuries and who had no apparent cardiovascular disease. In spite of the difficulty in differentiating between the $\alpha$-actin isoforms at the protein level, Vandekerckove et al. (3) showed that the skeletal isoform represented $20 \%$ of the total in one adult male who died in an automobile accident and in one patient with hypertrophic obstructive cardiomyopathy. It remains therefore un- 
clear whether or not cardiovascular diseases in man are accompanied by isoactin switches. It is also completely unknown whether there is gene switching with development in human hearts as has been seen in rodents.

We have undertaken the present study using a large set of normal and diseased human hearts to determine if the accumulations of the $\alpha$-actin isomRNAs are regulated in man during development, with aging, and with disease. We hypothesized, because of comparisons with the reexpression of a fetal phenotype in rat cardiac hypertrophy (reviews in references 1 and 2), that $\alpha$-actin mRNAs would be developmentally regulated and that the isoform predominant during the fetal stage would be up regulated with disease. To address these questions, the sarcomeric isoactin mRNA composition of human hearts was analyzed by two different types of assays, dot blots with specific cDNA probes and primer extensions with an oligonucleotide common to cardiac and skeletal $\alpha$-actins. Furthermore, the amounts of each isomRNA were quantitated by using as standards RNA transcripts derived from cloned human $\alpha$-actin sequences, and the total amount of sarcomeric actin mRNA was evaluated as a function of total poly $\left(\mathrm{A}^{+}\right)$RNA. Our results indicate that the $\alpha$-actin mRNA accumulations are developmentally regulated, but that they remain essentially constant in normal and failing adult human hearts.

Table I. Main Characteristics of Control Patients

\begin{tabular}{|c|c|c|c|}
\hline Patient No. & Age & Sex & Cause of death \\
\hline & $y r$ & & \\
\hline \multicolumn{4}{|l|}{ Adult } \\
\hline $\mathrm{C}_{2}$ & 27 & $\mathbf{M}$ & Asphyxiation \\
\hline $\mathrm{C}_{4}$ & 23 & $\mathbf{M}$ & Head trauma \\
\hline $\mathrm{C}_{5}$ & 40 & $\mathbf{M}$ & Suicide by gun \\
\hline $\mathrm{C}_{6}$ & 17 & $\mathbf{F}$ & Auto accident \\
\hline $\mathrm{C}_{7}$ & 30 & $\mathbf{M}$ & Auto accident \\
\hline $\mathrm{C}_{8}$ & 38 & $\mathbf{M}$ & Auto accident \\
\hline $\mathrm{C}_{9}$ & 22 & $\mathbf{M}$ & Auto accident \\
\hline $\mathrm{C}_{10}$ & 22 & $\mathbf{M}$ & Suicide by hanging \\
\hline $\mathrm{C}_{11}$ & 19 & $\mathbf{M}$ & Suicide by gun \\
\hline $\mathrm{C}_{12}$ & 21 & $\mathbf{F}$ & Auto accident \\
\hline $\mathrm{C}_{13}$ & 23 & $\mathbf{F}$ & Auto accident \\
\hline $\mathrm{C}_{15}$ & 17 & $\mathbf{F}$ & Auto accident \\
\hline \multicolumn{4}{|l|}{ Children } \\
\hline $\mathrm{Ch}_{1}$ & 0.25 & & Sudden death syndrome \\
\hline $\mathrm{Ch}_{2}$ & 3 & $\mathbf{M}$ & Drowning \\
\hline $\mathrm{Ch}_{3}$ & 7 & $\mathbf{F}$ & Auto accident \\
\hline $\mathrm{Ch}_{4}$ & 8 & $\mathbf{M}$ & Auto accident \\
\hline $\mathrm{Ch}_{5}$ & 12 & $\mathbf{F}$ & Auto accident \\
\hline & $w k$ & & \\
\hline \multicolumn{4}{|l|}{ Fetal } \\
\hline $\mathrm{FH}_{1}$ & 13 & & Death in utero \\
\hline $\mathrm{FH}_{2}$ & 17 & & Death in utero \\
\hline $\mathrm{FH}_{3}$ & 18 & & Death in utero \\
\hline $\mathbf{F H}_{4}$ & 29 & & Death in utero \\
\hline
\end{tabular}

All patients listed in this table had no known cardiovascular problems. C, control adult hearts; FH, fetal heart; Ch, children heart.

\section{Methods}

Patients. Hearts from four fetuses (13, 17, 18, and $29 \mathrm{wk}$ in utero), five children aged 3 mo to $12 \mathrm{yr}, 12$ patients with no apparent cardiovascular problems, and 15 patients with chronic end-stage heart failure were investigated. The 12 control hearts were obtained from the Soviet Union $(n=4)$, the United States $(n=7)$, and France $(n=1)$. Hearts from the Soviet Union came from accident victims and were removed between 0.5 and $3.0 \mathrm{~h}$ after the accident. The control patients from the United States and France included children who died from noncardiovascular related diseases and accident victims who were kept under intensive care as potential heart donors but were ultimately rejected for transplantation. The main characteristics of these patients are listed in Table I. The 15 failing hearts came from patients that underwent cardiac transplantation, and pertinent characteristics are presented in Table II. Most of the patients had already been analyzed for the amount of cardiac mRNAs encoding the sarcoplasmic reticulum ATPase and were therefore labeled as in the previous study (14). Left ventricular samples were taken from each heart, and when possible, from different regions of the left ventricular free wall (apex, middle, and base). Biopsy samples were also obtained from the liver and abdominal skeletal muscles of patients undergoing routine abdominal operative procedures for use as controls in the respective experiments. All samples were obtained under conditions approved by the committees for the protection of human subjects at the respective institutions. Immediately after sampling, the tissues were rinsed, blotted dry, frozen in liquid nitrogen, and stored at $-70^{\circ} \mathrm{C}$ until needed for the preparation of RNA.

RNA preparations. Total cardiac, skeletal, and liver RNAs were prepared by the method of Chirgwin et al. (15) by guanidine isothiocyanate extraction, cesium chloride gradient sedimentation, and two consecutive ethanol precipitations in the presence of sodium or potassium acetate. The RNA concentration was determined using standard spectrophotometric techniques. One absorbancy unit at $260 \mathrm{~nm}$ in a $1-\mathrm{cm}$ light path cuvette was assumed to be equal to $40 \mu \mathrm{g} / \mathrm{ml}$ of RNA. The RNA was stored at $-20^{\circ} \mathrm{C}$ as a suspension in $70 \%$ ethanol containing $0.3 \mathrm{M}$ potassium acetate at $\mathrm{pH}$ 5.5.

$R N A$ (dot) blots and quantification of total sarcomeric $\alpha$-actin and poly $\left(\mathrm{A}^{+}\right)$from human hearts. Dot blots of total human cardiac RNAs were prepared by denaturing total RNA at $65^{\circ} \mathrm{C}$ in $15 \times \operatorname{SSC}(1 \times$ SSC

Table II. Main Characteristics of Patients with Heart Failure

\begin{tabular}{cccc}
\hline Patient No. & Age & Sex & HW \\
\hline & $y r$ & & $g$ \\
$\mathrm{D}_{2}$ & 50 & $\mathrm{~F}$ & 410 \\
$\mathrm{D}_{3}$ & 49 & $\mathrm{M}$ & 410 \\
$\mathrm{D}_{4}$ & 43 & $\mathrm{M}$ & 435 \\
$\mathrm{D}_{5}$ & 41 & $\mathrm{M}$ & 475 \\
$\mathrm{D}_{6}$ & 40 & $\mathrm{M}$ & 360 \\
$\mathrm{I}_{1}$ & 48 & $\mathrm{M}$ & 310 \\
$\mathrm{I}_{2}$ & 48 & $\mathrm{M}$ & 550 \\
$\mathrm{I}_{3}$ & 31 & $\mathrm{M}$ & 320 \\
$\mathrm{I}_{4}$ & 51 & $\mathrm{M}$ & $?$ \\
$\mathrm{I}_{5}$ & 42 & $\mathrm{M}$ & 500 \\
AR & 53 & $\mathrm{M}$ & 583 \\
MR $_{\text {AVC }}$ & 27 & $\mathrm{~F}$ & 315 \\
AVC & 36 & M & 515 \\
IPH & 36 & $\mathrm{M}$ & 650 \\
& 47 & $\mathrm{~F}$ & $?$ \\
\hline
\end{tabular}

The patient classification corresponds to that used previously in (14). D, idiopathic cardiomyopathy; I, ischemic heart disease; AVC, partial atrioventricular canal; MR, mitral regurgitation; AR, aortic regurgitation; IPH, idiopathic pulmonary hypertension; HW, heart weight. 
$=0.15 \mathrm{M}$ sodium chloride and $0.015 \mathrm{M}$ sodium citrate) for $15 \mathrm{~min}$ and quenching on ice. Serial dilutions $(1.5,0.75,0.37$, and $0.19 \mu \mathrm{g})$ were applied to Hybond $\mathrm{N}$ nylon membranes (Amersham Corp., Arlington Heights, IL) using a minifold apparatus (Schleicher \& Schuell, Keene, $\mathrm{NH}$ ), and the RNA was fixed to the membranes by UV illumination $(0.6 \mathrm{~J})$ according to the manufacturer's instructions (Vilber Lourmat, France). For use as standards, plasmid generated $\alpha$-actin RNA transcripts complementary to human $\alpha$-actin mRNAs were prepared from human skeletal (pG78, a 400-bp fragment in pGEM3) and cardiac (pLK300, a 171-bp fragment in pBR322) specific cDNAs kindly provided by P. Gunning (16). After subcloning the insert of pLK300 into pGEM3 (pGLK300) and linearizing the plasmids by appropriate enzymatic digestion, RNA transcripts were obtained by promoter driven transcription using the endogenous T7 and SP6 promoters found in each plasmid, pG78 and pGLK300, respectively. Negative controls, transcripts identical to the $\alpha$-actin human RNAs, were prepared in exactly the same manner, except that the complementary promoter was used, i.e., SP6 for pG78 and T7 for pGLK300. All these transcripts were prepared using the SP6/T7 Transcription Kit (Boehringer-Mannheim, Inc., Indianapolis, IN), and the amount of RNA was determined by UV absorbance, as described above for total RNA. Serial dilutions of RNA containing both the bacterial promoter generated transcripts (1.5-0.012 fmol) and tRNA sufficient to equal the amount of total human RNA deposed on the membrane were applied to the Hybond membranes in parallel with the human total RNA. The radioactive probes for the two actins $\left(\sim 1.5 \times 10^{9} \mathrm{dpm} / \mu \mathrm{g}\right)$ were prepared from pG78 and pLK300. The inserts were released from the plasmid by enzymatic digestion and labeled in the presence of ${ }^{32} \mathrm{P}-\mathrm{dCTP}(800 \mathrm{Ci} /$ mol) essentially as described for the Amersham random prime kit, except that the primer/BSA solution was replaced by $1 \mu \mathrm{g}$ of an oligonucleotide specific for each insert (16), and $80 \mu \mathrm{g} / \mathrm{ml}$ BSA in a final reaction volume of $50 \mu \mathrm{l}$. Prehybridization and hybridization of the membranes were at $42^{\circ} \mathrm{C}$ in a buffer containing $250 \mu \mathrm{g} / \mathrm{ml}$ salmon sperm DNA, $50 \mathrm{ng} / \mathrm{ml}$ poly $\left(\mathrm{A}^{+}\right), 5 \times \mathrm{SSC}, 0.1 \%$ Ficoll, $0.1 \%$ polyvinylpyrollidone, $0.1 \% \mathrm{BSA}, 0.1 \%$ SDS and $50 \mathrm{mM}$ phosphate $\left(25 \mathrm{mM} \mathrm{HPO}_{4}\right.$ and $25 \mathrm{mM} \mathrm{H}_{2} \mathrm{PO}_{4}$ ), $\mathrm{pH}$ 6.5. After $16 \mathrm{~h}$ of hybridization, the blots were washed two times in $2 \times$ SSC, $0.1 \%$ SDS at room temperature, and two times at $50^{\circ} \mathrm{C}$ in $0.5 \times \mathrm{SSC}, 0.1 \% \mathrm{SDS}$. Blots were successively hybridized with each actin probe, and total poly $\left(\mathrm{A}^{+}\right)$for each human RNA was determined by hybridization of the membranes to $\mathrm{T} 4$ polynucleotide kinase $\gamma^{32} \mathrm{P}$ end-labeled oligo- $d T$ (25-30 mer) (Pharmacia Fine Chemicals, Piscataway, NJ) to sp act $1.4 \times 10^{8} \mathrm{dpm} / \mu \mathrm{g}$. Finally, as a control for the amount of RNA effectively bound to the filter from which the actin and poly $\left(\mathrm{A}^{+}\right)$contents could be normalized, the dehybridized membranes were rehybridized to a $\mathrm{T} 4$ polynucleotide kinase $\gamma^{32} \mathrm{P} 5^{\prime}$ end labeled $18 \mathrm{~S}$ oligonucleotide probe (17) diluted with unlabeled oligonucleotide to sp act $1.6 \times 10^{6} \mathrm{dpm} / \mu \mathrm{g}$. Hybridization and washing conditions of the two oligonucleotides were as described before (14). After each hybridization, the membranes were exposed to Cronex 4 film (DuPont Co., Wilmington, DE) using Quanta III intensifying screens (DuPont Co.) at $-70^{\circ} \mathrm{C}$ and at least three different exposure times were chosen to obtain densitometric scans (Shimadzu dualwavelength flying-spot scanner CS-9000) in the linear response range of the x-ray film (semilogarithmic plot). The concentration of each isoactin mRNA was calculated by comparisons with the signals obtained with the plasmid-derived RNAs and was expressed in femtomoles either per $1 \mu \mathrm{g}$ of total RNA or per 1 arbitrary unit of total poly $\left(\mathrm{A}^{+}\right) \mathrm{RNA}$. One arbitrary unit of total poly $\left(\mathrm{A}^{+}\right) \mathrm{RNA}$ was the intensity of the signal given by $1 \mu \mathrm{g}$ of liver total RNA. All values were normalized to the amount of $18 \mathrm{~S}$ RNA bound to the filter.

Determination of the respective amounts of $\alpha$-skeletal and $\alpha$-cardiac $m R N A s$ by primer extension analyses. The relative proportions of human skeletal and cardiac $\alpha$-actins were measured simultaneously in the same sample of RNA using a primer extension assay. This technique takes advantage of the differences in length of the $5^{\prime}$ noncoding region of each $\alpha$-actin mRNA and had previously been used to analyze the $\alpha$-actin mRNAs in the rat $(6,10,18)$. We used an 18 nucleotide primer with the sequence ${ }^{5}$ CG GCC CAC GAT GGA CGG G ${ }^{3}$. This sequence is conserved between the two human sarcomeric actin genes and corresponds to sequences coding for amino acids 31-37 for both human $\alpha$-skeletal (19) and human $\alpha$-cardiac actin (20). The oligomer was synthesized at the Pasteur Institute, purified from a 20\% polyacrylamide gel, and labeled at the $5^{\prime}$ end with $\gamma^{32} \mathrm{P}$ using the T4 polynucleotide kinase (Boehringer Mannheim, Inc.). 1 pmol of the purified and labeled primer was then added to 8 or $10 \mu \mathrm{g}$ of total RNA in the reverse transcriptase reaction (M-MLV reverse transcriptase, Bethesda Research Laboratories, Bethesda, MD) and incubated exactly as described (10). The precipitated and denatured ( $90 \%$ formamide) reaction products were separated on a $6 \%$ denaturing polyacrylamide/urea gel $(90 \mathrm{~W}$ for 2-3 h) along with a negative (total human liver RNA) and a positive (total human skeletal muscle RNA) control. Most RNAs were analyzed several times on different gels to ensure the reproducibility of the results. The relative position of the two transcribed fragments and the specificity of the method are shown in Fig. 1. With skeletal muscle $(S k)$, one distinct signal is seen between molecular weight markers of 194 and 234 nucleotides which corresponds well with the predicted value of 222 nucleotides for human $\alpha$-skeletal actin mRNA. From cardiac muscle $(C)$, two signals are seen, one of which migrates exactly at the same position as that seen with skeletal muscle and a second reverse transcript migrates somewhat faster than the 194 nucleotide marker and corresponds to the predicted length of 174 nucleotides for human $\alpha$-cardiac actin. In some experiments, a second signal which migrated slightly more quickly than the 222 nucleotide signal could be seen on the autoradiograms. By analysis with duplicate samples on the same gel or from other gels which showed only a single band of 222 nucleotides, it was determined that the more rapidly migrating band was also transcribed from $\alpha$-skeletal actin mRNAs; therefore, when these two bands were present, the signals were totaled and the sum of the two was included in all further calculations. It is conceivable that this second band of $\sim 218-220$ nucleotides resulted from the occasional premature termination by the reverse transcriptase on $\alpha$-skeletal actin mRNAs. There were no other major bands seen on these autoradiograms. The primer did not hybridize with RNA from the liver $(L)$ indicating that the 174 and 222 nucleotide bands are derived from sarcomeric $\alpha$-actins. We also verified that smooth muscle actin mRNAs did not interfere with the interpretation of these results. For this, two adult cardiac RNAs were primer extended with two human 18 mer oligonucleotides complementary either to smooth muscle $\alpha$-actin $\left({ }^{\prime} \mathrm{CG}\right.$ TCC CAC AAT GGA TGG G $\left.{ }^{3}\right)(21,22)$ or to smooth muscle $\gamma$-actin $\left({ }^{5}{ }^{\prime} C G\right.$ GCC CAC AAT GGA GGG $\mathrm{G}^{3^{\prime}}$ ) (23). These oligonucleotides differ by three and two bases, respectively, from those used in the primer extension analysis of sarcomeric actins, and correspond to amino acids 31-37 for both human smooth muscle $\alpha$ - and $\gamma$-actins (21-23). No other sequences were identified in these genes that more closely matched the 18 nucleotide primer conserved between the human sarcomeric actin genes. After primer extension with these smooth actin primers, no products corresponding to 222 or 174 nucleotides were seen in these assays (not shown), indicating that the extended products are derived only from striated muscle actins (see Fig. 1).

Reproducibility of the procedure (24) based on 16 pairs of duplicates, was $\pm 11 \%$ (for, example, a ratio of 60 , ranges from 66.6 to 53.4 ).

Assessment of actin iso-mRNAs by comparison of RNA hybridizations and primer extensions. In one series of experiments, skeletal muscle and cardiac muscle RNAs were simultaneously added in inversely proportional amounts of $0,25,50,75$, or $100 \%$ while maintaining a constant total amount of RNA. The percentage of the $\alpha$-actins from these RNA mixes was then determined by dot blot hybridization and by primer extension analysis as described. Fig. 2 shows the curves obtained by comparing the determined skeletal/sarcomeric actin mRNA with the theoretical ratio calculated from the value found in the $100 \%$ cardiac muscle RNA sample. As can be seen, both techniques show a linear accumulation of $\alpha$-skeletal actin transcripts with increasing amounts of skeletal muscle RNAs. This result implies that in samples with different concentrations of $\alpha$-actin isomRNAs both techniques can be used accurately to determine the percentage of these mRNAs in each sample. Based on these results, the majority of the human RNA 

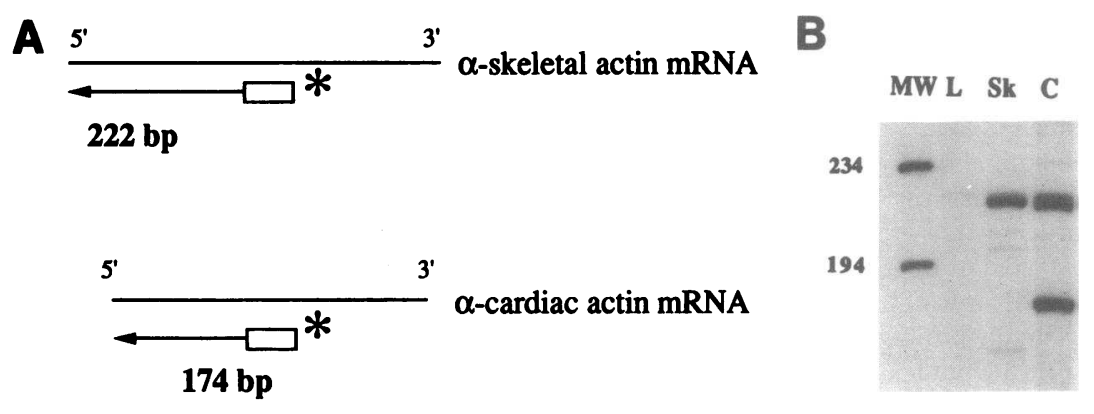

Figure 1. Primer extension analysis for human $\alpha$-cardiac and $\alpha$-skeletal actins. $(A)$ A synthetic 18-nucleotide oligonucleotide (open box), complementary to both $\alpha$-actins was labeled with ${ }^{32} \mathrm{P}$ and hybridized to total RNA. The annealed primer is then extended to the $5^{\prime}$ end by reverse transcriptase whose products can be resolved on denaturing acrylamide gels. $(B)$ Autoradiogram from a $6 \%$ denaturing gel. The first column shows the migration of the molecular weight markers $(M W)$. The products generated by primer extension are shown in the columns labeled $L, S k$, and $C$ (liver, skeletal muscle, and cardiac muscle, respectively). There

was no signal generated from liver RNAs. In adult skeletal muscle, only one product is detected which has a length of 222 bases. From cardiac muscle two products are detected. One corresponds to $\alpha$-skeletal actin and a second shorter extension product to $\alpha$-cardiac actin (174 bases). No other major extension products were observed from the gels.

samples were analyzed by primer extension analysis because the percentage of the two actin isomRNAs could be determined simultaneously.

Data analysis. The results are expressed as mean \pm SD. Statistical evaluations were performed by Student's $t$ test for paired observations, by two-way analysis of variance, and two-sample $t$ test for group to group comparisons, and one-way analysis of variance for comparisons between fetal and adult hearts. The threshold of significance was chosen as values of $P<0.05$.

\section{Results}

Skeletal and total $\alpha$-actin accumulate during development. To determine whether there is developmental regulation of $\alpha$-actin isomRNA accumulations, the percentage of sarcomeric $\alpha$-ac-

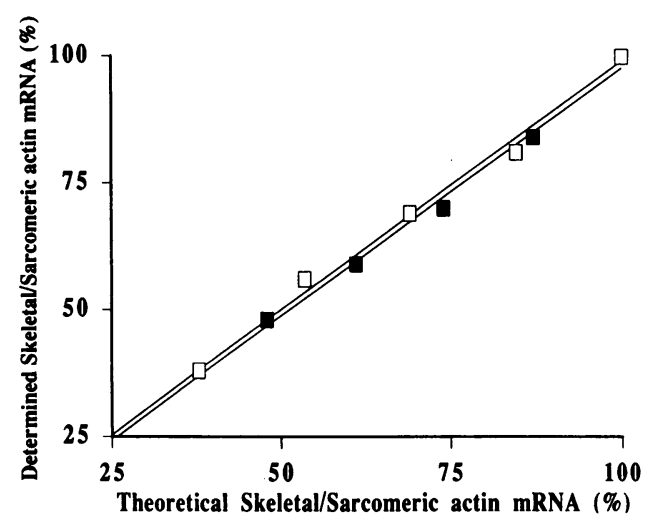

Figure 2. Actin isomRNA analysis by primer extension and RNA hybridization. Variable amounts of cardiac RNA from one human heart sample $C_{12}(8,6,4,2,0 \mu \mathrm{g})$ were mixed with skeletal muscle RNA $(0,2,4,6,8 \mu \mathrm{g})$. By dot blot analysis, the quantity of the $\alpha$-skeletal and $\alpha$-cardiac actin was determined by the simultaneous hybridization of the membrane bound cardiac/skeletal RNA mix and the plasmid generated cardiac and skeletal actin truncated transcripts used as standards with the labeled probes from pG78 ( $\alpha$-skel) and pGLK300 ( $\alpha$-card). The amount of each actin isomRNA was determined and the data expressed as the percent of $\alpha$-skeletal to total sarcomeric actin mRNA. Primer extensions were performed as described. The theoretical values for both techniques were calculated from the ratio for skeletal/sarcomeric actin mRNA found for the cardiac muscle RNA sample, i.e., $\mathbf{4 8}$ and $38 \%$ by primer extension and dot blot, respectively. The determined ratios obtained by PE (solid boxes) and dot blots (open boxes) were then plotted against the theoretical values. tins in ventricles was quantitated with dot blots using plasmid derived human actin RNAs as references and by primer extension. Fig. 3 shows the comparisons between fetal and adult ventricle sarcomeric actin expression (FH4, 29 wk in utero, and I1, $48 \mathrm{yr}$ ). In dot blot analysis (Fig. $3 A$ ), the $\alpha$-skeletal probe hybridized strongly with its homologous muscle control (adult skeletal muscle, Sk) and its antisense cRNA (+RNA $)^{\text {; }}$; whereas, no detectable or only faint signals were seen from liver-derived RNA or from sense cRNA (-RNA $)$ ). Conversely, the $\alpha$-cardiac probe hybridized strongly with its antisense cRNA, and only faintly with liver and skeletal muscle RNAs and with the sense plasmid (-RNA $)$. This hybridization pattern showed that each probe was indeed specific for its isomRNA, and that the plasmid-derived cRNA could be used as internal standards to quantify each isoform. The fetal and adult samples exhibited strikingly different hybridization patterns: FH4 and I1 RNAs hybridized weakly and strongly, respectively, with the $\alpha$-skeletal probe; whereas, both RNAs gave strong and almost equivalent signals with the $\alpha$-cardiac, poly $\left(\mathrm{A}^{+}\right)$, and $18 \mathrm{~S}$ probes. The results are consistent with the observation recently reported by Goldman and Wurzel showing in two human fetal hearts the absence of hybridization with an $\alpha$-skeletal probe (25). The absolute amounts for FH4 ( $\alpha$-skel $<0.03$ and $\alpha$-card $=0.10 \mathrm{fmol} / \mu \mathrm{g}$ of total RNA) and for I1 ( $\alpha$-skel $=0.64$ and $\alpha$-card $=0.61 \mathrm{fmol} / \mu \mathrm{g}$ of total RNA) indicated that the ratio skeletal/sarcomeric actin mRNA increases from 20 to $51 \%$. The corresponding primer extension analysis (Fig. $3 \mathrm{~B}$ ) also showed an increased intensity of the $\alpha$-skeletal band as compared to the $\alpha$-cardiac one, the ratio increasing from 18 to $62 \%$. Thus, the same conclusions could be drawn by both techniques, i.e., the ventricular isoactin mRNA pattern of expression changes from the fetal to the adult stage.

The complete results obtained in this study are presented in Fig. 4. Actin $\alpha$-skeletal mRNA is a minor component of the fetal ventricles (mean value $16.0 \pm 3.8 \%$ ) and does not change markedly just after birth (23\%). It increases during the first decade of life (mean value $48.0 \pm 6.1 \%$ ), and by 12 yr of age a drastic reversal of the pattern is apparent. At this time, $\alpha$-skeletal actin becomes the most abundant form (73\%), and remains so in adult hearts $(60.4 \pm 8.5 \%)$. The change between 3 mo and 12 yr was confirmed by both techniques ( 30 and $73 \%$, respectively, by dot blot vs. 23 and $73 \%$ by primer extension). Our mean value of $60.4 \%$ in the control adult hearts is consistent with that previously reported in one control heart $(50 \%$; reference 12 ), but it is markedly higher than the $20 \%$ determined by 


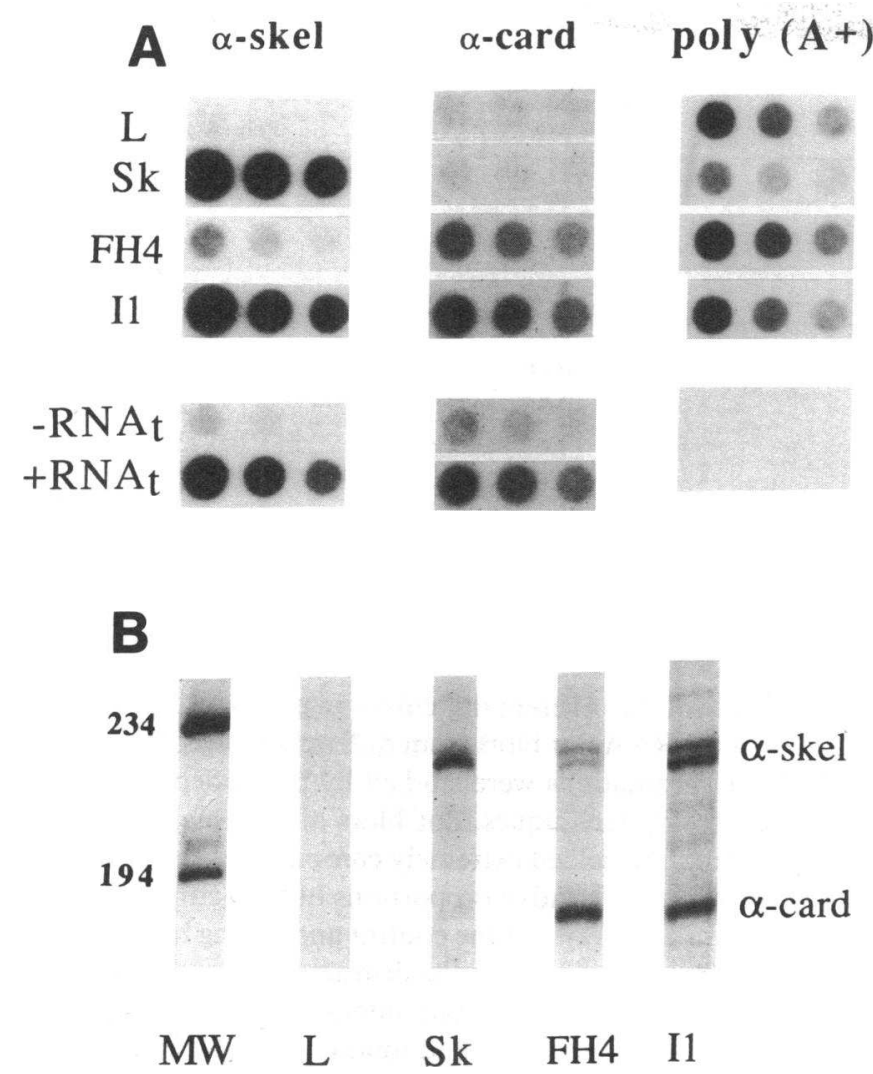

dot blot analysis by Bennetts et al. (13) in another control heart. We found no value of skeletal actin lower than $47 \%$ in any of our adult controls.

The use of skeletal and cardiac probes of identical specific activities and the addition of bacterial promoter generated actin sequences to the dot blots allowed us to determine the relative amount of total sarcomeric actin present in the various samples as a function of total poly $\left(\mathrm{A}^{+}\right)$RNA (Table III). We observed that total sarcomeric $\alpha$-actin mRNAs increase between the 29th wk of gestation and after birth relative to poly

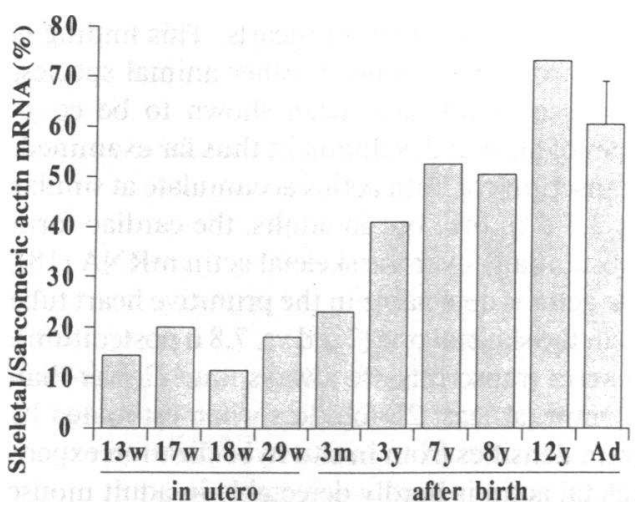

Figure 4. Human skeletal actin mRNA accumulates with development and aging. Relative sarcomeric actin contents with age were determined in utero and after birth by primer extension. The results are expressed as the percentage of skeletal actin mRNA to total sarcomeric actin mRNA. The percentage shown for the adult human hearts is the average of 12 human hearts and is expressed as \pm SD. $w$, weeks; $m$, months, $y$, years; $A d$, adult.

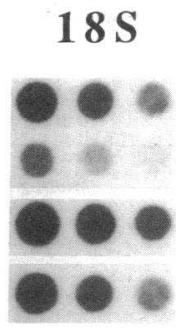

Figure 3. Developmental analysis of human cardiac RNA. $(A)$ Dot blot analysis of RNAs (1.5, 0.7, $0.35 \mu \mathrm{g})$ from liver $(L)$, skeletal muscle $(S k), 29$ wk-old fetal heart (FH4), adult heart $\left(\mathrm{I}_{1}\right)$, and bacterial promoter generated truncated human actin transcripts $(0.375,0.188,0.094 \mathrm{fmol})$ identical $\left(+\mathrm{RNA}_{\mathrm{t}}\right)$ or complementary $\left(-\mathrm{RNA}_{\mathrm{t}}\right)$ to human $\alpha$-skeletal and $\alpha$-cardiac actin. Actin signals were obtained by hybridization of the membranes to $\gamma^{32} \mathrm{P}$ labeled probes from pG78 ( $\alpha$-skeletal actin, $\alpha$-skel) and pGLK300 ( $\alpha$-cardiac actin, $\alpha$-card). Poly $\left(\mathrm{A}^{+}\right)$and $18 \mathrm{~S}$ ribosomal RNAs were determined by hybridization with oligo- $d T$ and complementary $18 \mathrm{~S}$ end labeled oligonucleotides, respectively. (B) Primer extension analysis with 10 $\mu \mathrm{g}$ of total RNA from the same RNAs used in $A$. Molecular weight markers $(M W)$ are indicated in the first column.

$\left(\mathrm{A}^{+}\right)$. This ratio apparently remains stable throughout the first $12 \mathrm{yr}$ of life. In the adult, there is a further increase in $\alpha$-actins to poly $\left(\mathrm{A}^{+}\right)$when compared with the ratios obtained in the juvenile and adult hearts. These data strongly suggest that the accumulations of actins are specific events independent of the basal activity of overall mRNA transcription. We also determined the amount of sarcomeric actin mRNA in adult skeletal muscle and we found that skeletal muscle contains $\sim 2$.8-fold more sarcomeric actin per microgram of RNA than cardiac muscle (compare $\mathrm{C}_{12}$ and skeletal muscle in Table III). This is in extremely good agreement with the value of 2.3 previously reported by Gunning et al. (12).

Further studies on RNAs isolated from the adult hearts were performed to determine if there were any possible sample differences due to delays in sampling time because of the differences in life support in the countries from which the samples were obtained. We were unable to demonstrate any significant differences between the amounts of skeletal actin RNAs in adult hearts of Russian $(55.9 \pm 9.9 \%, n=4)$, French $(62 \%, n$ $=1$ ), or American $(62.7 \pm 7.9 \%, n=7)$ patients. This lack of difference between the pooled groups suggests that variations in life support did not contribute or bias the results obtained in this study.

Heart failure. Cardiac tissue samples were obtained from 15 patients undergoing cardiac transplantation due to advanced stages of heart failure and analyzed. The percentage of $\alpha$-skeletal actin mRNA to sarcomeric actin mRNA from all pathologic hearts was $62.8 \pm 11.1 \%$, which is consistent with the $50 \%$ value reported for one failing heart (12). This percentage represents the mean of all the values obtained from the different regions of the left ventricles and is not statistically different from that found in control left ventricles. To test the potential 


\begin{tabular}{|c|c|c|c|c|}
\hline & Age & $\begin{array}{c}\text { Sarcomeric } \\
\text { actin mRNA }\end{array}$ & $\begin{array}{l}\text { Sarcomeric actin } \\
\text { mRNA/poly }\left(\mathrm{A}^{+}\right)^{*}\end{array}$ & Poly $\left(\mathrm{A}^{+}\right) / 18 \mathrm{~S}^{*}$ \\
\hline \multicolumn{5}{|c|}{ fmol/ $\mu \mathrm{g}$ total RNA } \\
\hline Liver & Adult & - & - & 1.0 \\
\hline $\mathrm{FH}_{4}$ & 29 wk in utero & 0.13 & $<0.17$ & 0.78 \\
\hline $\mathrm{Ch}_{1}$ & $3 \mathrm{mo}$ & 0.45 & 0.35 & 1.30 \\
\hline $\mathrm{Ch}_{2}$ & $3 \mathrm{yr}$ & 0.64 & 0.56 & 1.14 \\
\hline $\mathrm{Ch}_{5}$ & $12 \mathrm{yr}$ & 0.30 & 0.48 & 0.62 \\
\hline $\mathrm{C}_{12}$ & $21 \mathrm{yr}$ & 1.19 & 1.63 & 0.73 \\
\hline Skel muscle & Adult & 3.49 & 4.01 & 0.87 \\
\hline
\end{tabular}

All values were normalized relative to 18S RNA. * Values are expressed in arbitrary units.

of regional differences in $\alpha$-actin mRNA distributions in the explanted hearts, RNA was prepared from the base, midventricular wall, and the apex of the same heart and analyzed. Based on paired analyses, we were unable to demonstrate any regional differences in $\alpha$-actin accumulations in human heart (base vs. apex [ $n=8], 60 \% \pm 11$ vs. $56 \% \pm 7$; base vs. midwall [ $n$ $=6$ ], $58 \% \pm 11$ vs. $55 \% \pm 20$; midwall vs. apex $[n=6], 51 \% \pm 18$ vs. $53 \% \pm 9$ ). Additionally, we saw no evidence of differences in the relative amounts of the two sarcomeric $\alpha$-actins between patients with dilated cardiomyopathy, ischemic heart disease, or any of the other cardiac abnormalities (Fig. 5). Thus, we conclude that $\alpha$-actin mRNA accumulations do not change from the normal state with end-stage heart failure.

\section{Discussion}

The results presented here confirm that the two sarcomeric $\alpha$-actin transcripts are coexpressed in the human heart. It is further demonstrated that their accumulations are developmentally regulated, and that the proportion of the transcripts are maintained at a relatively constant level in both the normal and failing adult human ventricles.

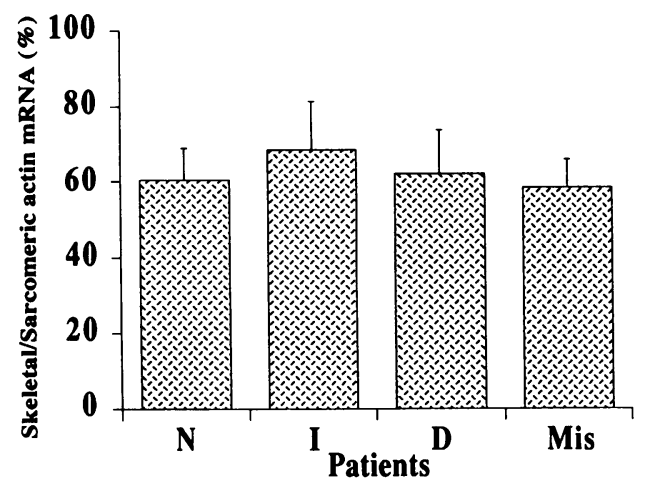

Figure 5. Human skeletal actin mRNA accumulations with heart failure are not different from those of normal hearts. Relative sarcomeric actin contents were determined by primer extension from control $(N)$ and diseased human hearts. Results are presented as the percentage of skeletal actin mRNA to sarcomeric actin mRNA \pm SD. Diseased human hearts were from patients with ischemic heart disease (I), idiopathic cardiomyopathy (D), and other miscellaneous (Mis) heart ailments (see Table II for the corresponding diseases).
Because of the inherent difficulties in precisely quantitating the results of RNA dot blots from different probes, the $\alpha$-actin mRNA accumulations were studied by two independent and complementary techniques, dot blots and primer extension. Both techniques yielded extremely comparable results, and we chose to study the relative proportions of the actins by primer extension in a majority of the control and failing human heart samples. This technique has the distinct advantage of indicating the proportion of the two sarcomeric actins from each RNA preparation simultaneously and unambiguously, and is therefore theoretically more accurate than dot blot analyses (18). It requires, however, undegraded RNAs, which is often a problem when dealing with human cardiac samples but was not for our samples because of rapid collection and careful storage. Indeed, all the RNAs that we used yielded two predominant bands corresponding to $\alpha$-skeletal and $\alpha$-cardiac actins. Moreover, it was previously shown for most of the human RNAs used in this study by Northern blot analysis to myosin heavy chain and $\mathrm{Ca}^{++}$ATPase specific cDNAs that they were not degraded (14). All this indicated that our experimental conditions allowed precise analysis of the human isoactin mRNA pattern.

The main finding of this study is that cardiac actin mRNA is the major isoform of the human fetal heart, whereas skeletal actin predominates in young and adult hearts. This finding is somewhat different from that found in other animal species, although both types of actin have been shown to be coexpressed at all stages of animal development thus far examined. In chick heart, transcripts for both actins accumulate at similar levels as early as $2.5 \mathrm{~d}$ in ovo, but in adults, the cardiac form predominates substantially over the skeletal actin mRNA (18). In mouse, cardiac actin is detectable in the primitive heart tube slightly earlier than the skeletal one ( $7.5 \mathrm{~d}$ vs. $7.8 \mathrm{~d}$ postcoitum), and the skeletal actin transcripts are always much lower than those of cardiac actin (at least 25-fold less when estimated by the respective grain densities from in situ hybridization experiments) (26). Skeletal actin is hardly detectable in adult mouse heart (27). In the hearts of late fetal and newborn rats, the mRNAs for both actins are present in almost equivalent amounts but cardiac actin is almost unique in adult animals (4-10). Man, therefore, is the only species so far studied in which skeletal actin mRNA increases in the heart after birth and accumulates at higher levels than cardiac actin mRNA in adults. 
At the protein level, skeletal actin only differs from cardiac actin by a Glu $\rightarrow$ Asp exchange at residues 2 and 3, and by exchange of Met $\rightarrow$ Leu and Ser $\rightarrow$ Thr at positions 299 and 358 , respectively. Due to this very strong similarity, classical immunological and biochemical techniques do not allow the quantification of both isoproteins in mixtures of the two. The only available procedure for doing this was developed by Vandekerckove et al. (3). Although elegant, this technique is delicate and difficult to perform. Using this technique, only two human hearts, one control and one pathologic, were analyzed by the authors. The ventricles and one atrium were reported to contain $\sim 20 \%$ skeletal isoactin, which corresponds well with the ventricular mRNA percentage found by Bennetts from another human adult heart (13). It would, however, be hazardous to propose from this sole analysis that isoprotein composition reflects isomRNA composition. Our results show variability from one heart to the other (see Fig. 4), and only a precise comparison of the protein and mRNA levels on the same heart would allow one to draw such a conclusion. For other large mammals, the situation appears analagous to that seen in man at the protein level. Skeletal isoactins account for $20 \%$ of the total actin protein in adult bovine and porcine hearts (3); however, the percentages of the mRNAs are currently unknown. It has been recently suggested that during terminal differentiation of skeletal muscle cells in vitro, RNA accumulations of actin and myosin light chain are regulated at both transcriptional and posttranscriptional levels (28). It is currently not possible to compare on a large series of human hearts, the actin isoprotein and isomRNA composition or to analyze in the human heart either the transcriptional activity of the actin genes, or the mRNA stabilities, and perhaps bovine and porcine cardiac cells could be used to address these regulatory questions.

What are the factors that might regulate the developmental changes that we have found in man? The promoter regions of human cardiac and skeletal actin genes have been extensively analyzed. They contain at least five types of upstream regulatory elements and current results indicate that very complex interactions take place between the transcriptional factors in these regions (review in reference 29); however, almost nothing is known concerning the sequences and the factors that interact with these sequences to confer muscle specificity of expression and that might be responsible for the up/down regulation of actin genes in cardiac muscle. Our data open further insights into these types of study by providing developmental stages corresponding to different patterns of expression. Recent studies have shown that thyroid hormone (10) and peptide growth factors TGF $\beta 1$ and bFGF (11) up-regulate the skeletal actin gene in the adult heart and in neonatal cardiac cells, respectively. It would therefore be of further interest to examine the hypothesis that these components participate in the control of actin genes during human cardiac development.

With human heart failure, apparently no transition to a putative fetal actin isoform pattern occurs (Fig. 5). Skeletal actin transcripts remain the most abundant isomRNA at $62 \%$ of total sarcomeric actin. In rat, after a hemodynamic overload, skeletal actin transcripts rapidly and transiently accumulate $(5,8)$. The significance of this accumulation is unknown. We are unable to say whether human hearts synthesize an even higher percentage of skeletal actin isomRNAs in earlier stages of heart disease and therefore cannot rule out similar transitory changes. Our results, however, strongly suggest that the molecu- lar basis of thin filament disregulation during heart failure is not actin.

Finally these results provide evidence of independent regulation of the multigene families encoding the two main proteins responsible for human cardiac contraction, myosin heavy chain, and actin. In human ventricles, $\beta$-myosin heavy chain is almost the exclusive form present at all ages, even though the $\alpha$ form seems to increase after birth $(30,31)$. One would like to hypothesize that these two sarcomeric proteins would be highly and mutually coordinated at the transcriptional and/or translational levels and that this coordination should in turn lead to the most efficient state of contraction under normal and pathological conditions. This, however, does not seem to be the case and further attempts to elucidate the mechanisms of cardiac myogenesis in man will be needed to account for these independent regulations.

\section{Acknowledgments}

We are indebted to P. Gunning, S. Dunwoodie, C. Sutherland, and E. Hardeman for the gift of the actin clones and to L. Kedes for his encouragement during this study. We wish to thank Ms. C. Wisnewsky for preparing the RNAs and we acknowledge the assistance of Drs. $R$. Maddi, J. Fox, F. Schoen, Brigham and Women's Hospital, Dr. V. Saks, Moscow Heart Institute, Dr. F. Sreter, Boston BioMedical Research Institute, Drs. C. Cabrol, I. Gandjbakhch, A. Pavie, Department of Cardiovascular Surgery, CHU Pitié-Salpêtrière, Paris, France, Dr. D. Gros, University of Aix-Marseille, Marseille, France, and Dr. G. Butler-Browne, INSERM Unité 262, Paris, France, for their help in collecting the samples for use in these experiments.

This work was supported by grants from the INSERM (CAR 487018), the Association Française contre les Myopathies, and the Caisse Nationale d'Assurance Maladie des Trovailleurs Salariés. Dr. K. R. Boheler is the recipient of a fellowship from La Fondation de la Recherche Médicale and Dr. L. Carrier is the recipient of a fellowship from L'Association Française Contre les Myopathies.

\section{References}

1. Nadal-Ginard, B., and V. Mahdavi. 1989. Molecular basis of cardiac performance. Plasticity of the myocardium generated through protein isoform switches. J. Clin. Invest. 84:1693-1700.

2. Lompré, A. M., J. J. Mercadier, and K. Schwartz. 1990. Changes in gene expression during cardiac growth. Intern. Rev. Cytol. 124:137-186.

3. Vandekerckove, J., G. Bugaisky, and M. Buckingham. 1986. Simultaneous expression of skeletal muscle and heart actin proteins in various striated muscle tissues and cells. A quantitative determination of the two actin isoforms. J. Biol. Chem. 261:1838-1843.

4. Mayer, Y., H. Czosnek, P. E. Zeelon, D. Yaffe, and U. Nudel. 1984. Expression of the genes coding for the skeletal muscle and cardiac actins in the heart. Nucleic Acids Res. 12:1087-1100.

5. Schwartz, K., D. de la Bastie, P. Bouveret, P. Oliviéro, S. Alonso, and M. Buckingham. 1986. $\alpha$-Skeletal muscle actin mRNA's accumulate in hypertrophied adult rat hearts. Circ. Res. 59:551-555.

6. Bishopric, N. H., P. C. Simpson, and C. P. Ordhal. 1987. Induction of the skeletal $\alpha$-actin gene in $\alpha 1$-adrenoreceptor-mediated hypertrophy of rat cardiac myocytes. J. Clin. Invest. 80:1194-1199.

7. Carrier, L., P. Duc, K. R. Boheler, E. Lakatta, and K. Schwartz. 1990. Regulation of sarcomeric actins in the rat heart during early development and aging. In Geisinger Symposium: Molecular Mechanisms of Cellular Growth. 1720 June 1990, Danville, PA

8. Izumo, S., B. Nadal-Ginard, and V. Mahdavi. 1988; Protooncogene induction and reprogramming of cardiac gene expression produced by pressure overload. Proc. Natl. Acad. Sci. USA. 85:339-343.

9. Schiaffino, S., J. L. Samuel, D. Sassoon, A. M. Lompré, I. Garner, F. Marotte, M. Buckingham, L. Rappaport, and K. Schwartz. 1989. Nonsynchronous accumulation of $\alpha$-skeletal actin and $\beta$-myosin heavy chain mRNAs during early stages of pressure-overload-induced cardiac hypertrophy. Circ. Res. 64:937-948.

10. Winegrad, S., C. Wisnewsky, and K. Schwartz. 1990. Effect of thyroid hormone on the accumulation of mRNAs for skeletal and cardiac $\alpha$-actin in 
hearts from normal and hypophysectomized rats. Proc. Natl. Acad. Sci. USA. 87:2456-2460.

11. Parker, T. G., S. E. Packer, and M. D. Schneider. 1990. Peptide growth factors can provoke "fetal" contractile protein gene expression in rat cardiac myocytes. J. Clin. Invest. 85:507-514.

12. Gunning, P., P. Ponte, H. Blau, and L. Kedes. 1983. $\alpha$-Skeletal and $\alpha$-cardiac actin genes are coexpressed in adult human skeletal muscle and heart. Mol. Cell. Biol. 3:1985-1995.

13. Bennetts, B. H., L. Burnett, and C. G. dos Remedios. 1986. Differential coexpression of $\alpha$-actin genes within the human heart. J. Mol. Cell. Cardiol. 18:993-996.

14. Mercadier, J. J., A. M. Lompré, P. Duc, K. R. Boheler, J. B. Fraysse, C. Wisnewsky, P. D. Allen, M. Komajda, and K. Schwartz. 1990. Altered sarcoplasmic reticulum $\mathrm{Ca}^{2+}-\mathrm{ATPase}$ gene expression in the human ventricle during endstage heart failure. J. Clin. Invest. 85:305-309.

15. Chirgwin, J. M. A. E. Przybyla, R. J. Mac Donald and W. J. Rutter 1979. Isolation of biologically active ribonucleic acid from sources enriched in ribonucleases. Biochemistry. 18:5294-5299.

16. Gunning, P., T. Mohun, S. Y. Ng, Ponte, P., and L. Kedes. 1984. Evolution of the human sarcomeric-actin genes: evidence for units of selection within the 3' untranslated regions of the mRNAs. J. Mol. Evol. 20:202-214.

17. Mendez, R. E., J. M. Pfeffer, F. V. Ortola, K. D. Bloch, S. Anderson, J. G. Seidman, and B. M. Brenner. 1987. Atrial natriuretic peptide transcription, storage and release in rats with myocardial infarction. Am. J. Physiol. 253:H1449H1455.

18. Ordhal, C. P. 1986. The skeletal and cardiac $\alpha$-actin genes are coexpressed in early embryonic striated muscle. Dev. Biol. 117:488-492.

19. Taylor, A., H. P. Erba, G. E. O. Muscat, and L. Kedes. 1988. Nucleotide sequence and expression of the human skeletal $\alpha$-actin gene: evolution of functional regulatory domains. Genomics. 3:323-336.

20. Hamada, H., M. G. Petrino, and T. Kakunaga. 1982. Molecular structure and evolutionary origin of human cardiac muscle actin gene. Proc. Natl. Acad. Sci. USA. 79:5901-5905.
21. Ueyama, H., H. Hamada, N. Battula, and T. Kakunaga. 1984. Structure of a human smooth muscle actin gene (aortic type) with a unique intron site. $\mathrm{Mol}$. Cell. Biol. 4:1073-1078.

22. Reddy, S., K. Ozgur, M. Lu, W. Chang, S. R. Mohan, C. C. Kumar, and H. E. Ruley. 1990. Structure of the human smooth muscle $\alpha$-actin gene. Analysis of a cDNA and 5' upstream region. J. Biol. Chem. 265:1683-1687.

23. Miwa, T., and $S$. Kamada. 1990. The nucleotide sequence of a human smooth muscle (enteric type) $\gamma$-actin cDNA. Nucleic Acids Res. 18:4263.

24. Henry, R. J. 1964. Clinical Chemistry. Principles and Techniques. Harper and Row Publishers, Inc., New York. 125 pp.

25. Goldman, B., and J. Wurzel. 1991. Cardiac but not skeletal actin is expressed in human fetal heart muscle cells in vivo and in vitro. J. Cell. Biochem. 15(Suppl. C):161.

26. Sassoon, D. A., I. Garner, and M. Buckingham. 1988. Transcripts of $\alpha$-cardiac and $\alpha$-skeletal actins are early markers for myogenesis in the mouse embryo. Development. 104:155-164.

27. Minty, A. J., S. Alonso, M. Caravatti, and M. Buckingham. 1982. A fetal skeletal muscle actin mRNA in the mouse and its identity with cardiac actin mRNA. Cell. 30:185-192.

28. Cox, R. D., I. Garner, and M. Buckingham. 1990. Transcriptional regulation of actin and myosin genes during differentiation of a mouse muscle cell line. Differentiation. 43:183-191.

29. Gustafson, T. A., and L. Kedes. 1989. Identification of multiple proteins that interact with functional regions of the human cardiac $\alpha$-actin promoter. Mol. Cell. Biol. 9:3269-3283.

30. Mercadier, J. J., P. Bouveret, L. Gorza, S. Schiaffino, W. A. Clark, R. Zak, B. Swynghedauw, and K. Schwartz. 1983. Myosin isoenzymes in normal and hypertrophied human ventricular myocardium. Circ. Res. 53:52-62.

31. Bouvagnet, P., S. Neveu, M. Montoya, and J. J. Léger. 1987. Developmental changes in the human cardiac isomyosin distribution: an immunohistochemical study using monoclonal antibodies. Circ. Res. 61:329-336. 